Bol. Acad. peru. leng. 56. 2013 (53-73)

\title{
LOS ENIGMAS DE SOR JUANA COMO ARTEFACTOS DEL ENTENDIMIENTO
}

\section{LES ÉNIGMES DE SOR JUANA COMME DES ARTEFACTS DE L'ENTENDEMENT}

\section{THE ENIGMAS OF SOR JUANA AS DEVICES OF UNDERSTANDING}

\author{
Jesús Ernesto Ortiz-Díaz
}

\section{Resumen:}

A dos años de la tormenta levantada por la Carta Atenagórica y, precisamente, dos años antes de su muerte, Sor Juana envió a una academia de monjas portuguesas (A Casa do Prazer) — asiduas lectoras no solo de materias religiosas - un conjunto de veinte acertijos que han merecido poca atención por parte de la crítica de la obra sorjuanina. La brevedad de dichas composiciones y su carácter hermético — sin pasar por alto el hecho de que su autora no les haya dado solución definitiva alguna- han postergado el que se les otorgue la importancia que detentan al ser, quizá, la última obra acabada - concebida como una unidad en sí- de la escritora novohispana.

¿Qué importancia tiene esta veintena de composiciones, escritas por una monja, encaminadas al divertimiento de otras monjas? ¿Qué significación adquieren al constituir una de las últimas obras escritas por su autora después de que esta acatase el silencio que le fue impuesto? ¿Son una 
curiosidad atípica, un rasgo que desentona en la fisonomía regular de su producción?

Afirmo que Sor Juana en sus Enigmas ofrecidos a la Casa do Prazer, crea un artificio — de índole literaria - a través del cual posibilita, desde el silenciamiento público al que fue sometida, el ejercicio del libre albedrío en el marco de las reglas conventuales. La elección en la forma de dicho aparato es sumamente importante porque se sirve de un género popular - el acertijo o quisicosa - asociado con el espacio de lo doméstico y lo cotidiano - dominio de la mujer - para articular y debatir en terrenos de lo que era lo indecible para monjas y mujeres: la teología y las otras ciencias.

\section{Résumé:}

Deux ans après la tempête soulevée par la «Carta Atenagórica » et, précisément, deux ans avant sa mort, Sor Juana envoya à une académie de religieuses portugaises (A Casa do Prazer) -lectrices assidues de matières non seulement religieuses - un ensemble de vingt devinettes auxquelles les critiques de l'œuvre de Sor Juana n'ont accordé que peu d'attention. La brièveté de ces textes et leur caractère hermétique — sans oublier le fait que leur auteur ne leur ait donné aucune solution définitive- ont fait qu'on ne reconnaisse pas leur réelle importance, en tant que, probablement, dernière œuvre achevée — conçue comme une unité en soi- de l'écrivaine de Nouvelle Espagne.

Quelle importance a cette vingtaine de compositions, écrites par une religieuse, pour le divertissement d'autres religieuses ? Quel sens prennent-elles du fait de constituer une des dernières œuvres écrites par leur auteur, après avoir obéi au silence qu'on lui avait imposé ? S'agitil d'une curiosité atypique, d'un trait dissonant dans la physionomie régulière de sa production?

Dans ses «Énigmes » offerts à la Casa do Prazer, j'affirme que Sor Juana crée un artifice — de nature littéraire- permettant, depuis la mise sous silence publique auquel elle fut soumise, l'exercice du librearbitre dans le cadre des règles conventuelles. Le choix dans la forme de ce dispositif est extrêmement important car elle se sert d'un genre populaire — la devinette ou casse-tête— associé à l'espace domestique et quotidien — domaine de la femme - afin d'articuler et de débattre 
dans les domaines de ce qui était indicible pour les religieuses et les femmes : la théologie et les autres sciences.

\section{Abstract:}

Two years after the storm raised by the Carta Atenagórica (Letter Worthy of Athena) and, precisely two years before her death, Sor Juana sent to an Academy of Portuguese nuns (A Casa do Prazer) — assiduous readers not only of religious matters - a set of 20 riddles that have received little attention from the critics of her work. The brevity of these writings and their hermetic nature - taking into account the fact that the author has not given them a ultimate solution - have postponed being given the importance they deserve, for they might be the last finished work — conceived as a unit in itself- of the New-Spanish writer.

What importance does this score of writings have, written by a nun to the amusement of other nuns? What significance do they acquire by being one of her last written works after having complied with the silence imposed on it? Are they an atypical curiosity, a feature that is out of place in the average physiognomy of her production?

In her Enigmas offered to the Casa do Prazer we affirm that Sor Juana creates a trick of literary nature which, in the context of monastic rules, enables the exercise of free will from the public silencing to which she was subjected. The election of such device is extremely important because it makes use of a popular genre - the riddle or conundrum - associated with domestic and daily life — under the woman's control — in order to articulate and debate on grounds of what was unspeakable to nuns and women: theology and the other sciences.

Palabras clave: literatura mexicana; Sor Juana Inés de la Cruz; los Enigmas.

Mots clés: littérature mexicaine; Sor Juana Inés de la Cruz; les « Énigmes ».

Key words: mexican literature; Sor Juana Inés de la Cruz; Enigmas.

Fecha de recepción: $\quad$ 03/04/2013

Fecha de aceptación: $\quad$ 28/10/2013 
“¿Cuál puede ser el cuidado que, libremente imperioso, se hace a sí mismo dichoso y a sí mismo desdichado?" Sor Juana Inés de la Cruz, enigma $6 .^{\circ}$

"Lo que solo he deseado es estudiar para ignorar menos". Sor Juana Inés de la Cruz, Carta a Sor Filotea de la Cruz

Me propongo hacer dialogar a los Enigmas con el poema que la mayoría de los estudiosos de la obra de Sor Juana ha coincidido en señalar como el texto central, the very kernel — para citar un verso de Jorge Luis Borges - de su quehacer literario. Me refiero a "El sueño", en tanto dicho poema constituye una suerte de crisol donde confluyen todas las sílabas que componen la poética de la poeta novohispana, pues, como afirma Margarita Peña "[1]a obra de Sor Juana en su totalidad se antoja un canto al entendimiento, a la libertad de acción a través del intelecto" (2005: 180). Comenzaré, pues, este trabajo con una breve reseña del descubrimiento de los manuscritos en los que se hallaron los Enigmas para, luego, pasar a una revisión de su fortuna crítica con dos propósitos. El primero de ellos es detallar las interpretaciones - nada numerosas con respecto a la bibliografía que han generado otros textos de la monja jerónima- que esta obra ha suscitado entre los especialistas del campo; el segundo propósito es enmarcar una nueva interpretación de los Enigmas en el corpus sorjuanino, la cual propongo y constituye la segunda parte de este artículo.

En 1968, Enrique Martínez López comunicó el hallazgo, en la Biblioteca Nacional de Lisboa, de una colección de versos escritos por Sor Juana. Se intitulaban Enigmas ofrecidos a la discreta inteligencia de la soberana Asamblea de la Casa del Placer, por su más rendida y aficionada Soror Juana Inés de la Cruz, Décima Musa ${ }^{1}$. Habían permanecido inéditos hasta entonces desde 1695, fecha en que se los databa en el manuscrito. El

1 Los dio a conocer a través de una ponenecia en el tercer Congreso Internacional de Hispanistas que se celebró en el Colegio de México. Posteriormente, su trabajo fue publicado en la Revista de Literatura de Madrid bajo el título de "Sor Juana Inés de la Cruz en Portugal: un desconocido homenaje y versos inéditos". 
primer tomo de las Obras completas de Sor Juana — publicado en 1952 que tan cuidadosamente dirigiera el padre Alfonso Méndez Plancarte, no mencionaba en ninguna de sus páginas la existencia de los Enigmas. Ni siquiera - comenta Angelo Morino - los alude el sacerdote en la lista de obras desaparecidas o apócrifas de la religiosa novohispana. De modo semejante, Octavio Paz, que habría de publicar sus Trampas de la fe una docena de años más tarde (1982), tampoco haría alusión a los Enigmas en ese libro suyo que se convertiría en punto de partida de mucha de la crítica que estudia la obra de Sor Juana actualmente.

Los manuscritos en los que Martínez López encontró las copias (ninguna autógrafa, desgraciadamente) de los Enigmas (Oitavas a varios asumptos y Collecção de poesias e prosas de differentes auctores que ajuntou a curiosidade de José Freyre de Monterroyo Mascarenhas ${ }^{2}$ ) le permitieron preparar la primera edición crítica en la cual despejaba las incógnitas sobre la autoría de Sor Juana al cotejar la retórica de dichos textos con otros, principalmente de la lírica personal, de la poeta. Sin embargo, no sería hasta 1994 que Antonio Alatorre, fundamentando su estudio ya no solo en dos, sino en cuatro manuscritos - los otros dos también encontrados en la misma biblioteca portuguesa y reproducidos, asimismo, por copistas en el siglo XVIII ${ }^{3}$ - llevaría a la imprenta la que es hoy la versión más reputada de los Enigmas entre la crítica sorjuanina. Su edición, como lo había sido la de Martínez López, es un estudio crítico de los veinte acertijos que escribió Sor Juana y de los textos que los acompañan, los cuales Alatorre calcula habrían sido compuestos entre $1691 \mathrm{y}$ finales de 1692.

El pequeño volumen que son los Enigmas está constituido por veinte cuartetos a los que anteceden otros dos textos escritos por Sor Juana: un romance que sirve de dedicatoria y un soneto que hace las

2 En lo referente al manuscrito Oitavas a varios asumptos (referencia FG 3314), los Enigmas se encuentran en el tercer volumen (424-454); mientras que aparecen en el cuarto de Collecção de poesias e prosas de differentes auctores que ajuntou a curiosidade de José Freyre de Monterroyo Mascarenhas, Coleçcão Pombaliana, código 129 (folios 18r-26r).

3 Estos otros dos manuscritos corresponden a las referencias 3273 (folios 40r-50v) y 3229 (folios 1r-18v) y también se encuentran en la Biblioteca Nacional de Lisboa.

Bol. Acad. peru. leng. 56(56), 2013 
veces de prólogo. Además de ello, hay otras piezas tanto en prosa como en verso (nueve en total) que acompañan las composiciones de la poeta y que, o bien son loores escritos por las monjas portuguesas de la Casa do Prazer o por la Condesa de Paredes, o bien son textos que dan fe de la probidad moral de los acertijos ${ }^{4}$.

La recepción crítica de los Enigmas ha sido bastante inconstante. Quizá por su tardío descubrimiento, tal vez por su carácter hermético o por el hecho de que Sor Juana no les haya dado solución definitiva alguna, la lectura de sus enigmas ha propiciado principalmente dos actitudes encontradas entre los críticos (dejando de lado la poca atención que, en general, han suscitado a buena parte de la crítica si se considera, como ya se dijo más arriba, por ejemplo, la gran cantidad de tinta que se vierte en el estudio de otras de sus obras). La primera actitud o postura - a la cual se adscribe el presente artículo_ - frente a los Enigmas intenta adjudicarles significación dentro de la obra y la vida de la poeta novohispana al estudiarlos como una muestra de aquella agudeza e ingenio, tan propia del Barroco y, asimismo, como característica del espíritu especulativo de Sor Juana. Es por ello que los críticos realizan amplias investigaciones en la historia literaria para hacer conversar a los Enigmas con toda una larga tradición del acertijo o quisicosa en la tradición occidental (Enrique Martínez López, Antonio Alatorre y Georgina Sabat de Rivers5).

La otra actitud que ha tomado la crítica con respecto a los acertijos se da gracias a la aplicación de posturas teóricas posteriores o por medio de la utilización de la obra misma de Sor Juana para interpretarlos. Esta postura intenta leer mensajes cifrados en los Enigmas o, incluso, declaraciones de feminismo por parte de la poeta (así lo han hecho Yadira Munguía y Stephanie Kirk).

4 Para un comentario más detallado de los textos que acompañan los Enigmas, ver el artículo de Georgina Sabat de Rivers "Contemporáneos de Sor Juana; las monjas portuguesas y los Enigmas (con soluciones)".

5 Georgina Sabat de Rivers sigue esta línea puesto que su estudio parte y se fundamenta en las aportaciones y descubrimientos tanto de Martínez López como de Alatorre con la finalidad de proponer respuestas a los enigmas. 
La postura de Enrique Martínez López, Antonio Alatorre, Georgina Sabat de Rivers y Angelo Morino bien podría resumirse en la siguiente afirmación de este último: "los Enigmas — aunque no añadan mucho a la obra- permiten decir algo más por lo que se refiere a la vida de Juana Inés de la Cruz". Aunque las posiciones de Martínez López y Alatorre no sean tan radicales, sí coinciden con las de Morino al otorgarles estimación a los Enigmas por ser una de las últimas obras de Sor Juana, por las especiales circunstancias en que estos fueron escritos y por su naturaleza atípica dentro del amplio corpus de la obra sorjuanina. El esmero filológico y la concienzuda investigación de archivo que respalda las investigaciones de Martínez López y Alatorre han sido, sin duda, fundamentales para la reconstrucción de las condiciones en las cuales los Enigmas y las piezas que los anteceden habrían sido gestados. Gracias a sus trabajos ha sido posible imaginar la fama que detentaría Sor Juana en Portugal entre aquellas monjas que constituían esa academia tan sugestivamente llamada Casa do Prazer y que le escribieron sendos elogios a la escritora novohispana.

En su edición crítica de 1994, Alatorre, después de rastrear la genealogía del género y tradición del enigma en la literatura hispánica y explicar las circunstancias que rodearían la escritura del texto por parte de Sor Juana y aquellos de sus amigas que aparecen también en los cuatro manuscritos que utiliza, se aventura a dar su propia interpretación de la finalidad y la naturaleza de los Enigmas y su relación con el resto de la obra sorjuanina. En primer lugar, Alatorre asevera que se trata de una obra que no fue destinada para cualquier tipo de lectores, debido a que cuanto está escrito entraña no poca competencia de la cultura letrada de la época por parte de quien lo leyese: "No se dirigen a un público municipal y espeso, sino al grupo selecto de aficionados a sutilezas poéticas; no son respuestas insulsas a una serie de preguntas pedestres y estereotipadas, sino preguntas destinadas a hacer pensar" (1994: 12).

Asimismo, el crítico mexicano concibe esta veintena de composiciones como depositaria del espíritu especulativo tan característico de la escritura de Sor Juana, lo cual hace, a la vez, irrebatible la adjudicación de su autoría: “iCómo reluce en ellos su 'marca de fábrica'! Cada 'enig- 
ma' nos da, in nuce, una muestra de esas especulaciones cuasi-metafísicas sobre los sentimientos humanos a que tan dada fue su mente laberíntica" (Alatorre 1994: 13).

En este sentido, tanto para Alatorre, como para mí —aunque por motivos distintos - es irrelevante intentar encontrar soluciones a cada uno de los acertijos propuestos por Sor Juana porque sería solo ella quien podría proporcionarlas. En su lugar, Alatorre sugiere que la pluralidad de interpretaciones podría incrementar el interés de las discusiones que se darían alrededor de los Enigmas: "¿Y por qué no pensar en una pluralidad de interpretaciones? La única capaz de decidir entre varias respuestas cuál era la 'acertada' hubiera sido Sor Juana [...]. [L]a pluralidad y confrontación de interpretaciones podría acrecentar el interés del juego" (1994: 52-53).

En todo momento, Alatorre está consciente de que las destinatarias del texto de Sor Juana son las monjas portuguesas que formaban la academia literaria Casa do Prazer, quienes de paso entenderían perfectamente las condiciones desde las cuales la escritora y religiosa novohispana escribía la totalidad de su obra: "Las monjas de la Casa del Placer eran las lectoras ideales de esos textos de la Inundación Castálida, las más entendedoras, las más preparadas para captar no digamos el mensaje, sino las consecuencias del mensaje" (1994: 27-28).

Sin embargo, Alatorre, constantemente, evita leer más allá con respecto a esta empatía que se establecería entre dichas monjas y Sor Juana. Es esta zona gris, precisamente, el enfoque del estudio de Stephanie L. Kirk. Esta investigadora concibe los Enigmas como proyecto clandestino en el marco de una agenda de disidencia, feminismo y resistencia por parte de Sor Juana:

I propose an analysis of the literary work of the nuns of the Casa del Placer in light of the solidarity implied by the mobilization of a virtual

6 Discusiones muy al estilo de los salones literarios que abundaban en Europa y la América Española en los siglos XVII y XVIII y, seguramente, en el locutorio del convento en que Sor Juana recibía a la crème de la crème de los letrados — legos y religiosos — novohispanos. 
and utopian all-female writing community that challenged the Church's disapproval of female intellectual activity via the establishment of a learned community of scholarly women -in which Sor Juana and her friend and mentor the Condesa de Paredes were participants, together with Portuguese nuns from several different convents (2007: 130).

Kirk ve como motor para la escritura de los Enigmas y de los textos que acompañan a estos una encubierta "alianza intelectual entre mujeres". El problema de la lectura de Kirk radica, desde mi punto de vista, en su desatendimiento del contexto en el que se produjeron estos escritos frente a un favorecimiento de la lente de interpretación feminista, lo cual genera un desbalance. Así, Kirk realiza cuatro conclusiones respecto a los Enigmas. La primera es que el conjunto de textos de Sor Juana, la Condesa de Paredes y las monjas portuguesas parodiaba la estructura tradicional de un libro. La segunda, que la naturaleza de lo dicho en los Enigmas revelaba que la Casa do Prazer y sus actividades eran clandestinas. La tercera, que los escritos de Sor Juana, la Condesa de Paredes y las monjas portuguesas manifestaban la creación, a través del texto, de una utopía femenina contra el silenciamiento patriarcal. La cuarta conclusión es que la presencia en todos estos textos de un espíritu que evidencia una "mockery of heterosexual love and those who choose to put themselves in this path" (2007: 174). Y es que para Kirk los veinte acertijos que escribió Sor Juana y las otras piezas que los acompañan intentan ser un libro que, sirviéndose de las estrategias de la parody y mimicry favorecería un amor entre mujeres en el marco del ejercicio de la razón: “This love forms part of a masculinist paradigm, a patriarchal order, that Sor Juana and the other women of the Casa del Placer have rejected in favor of an all-female love predicated on the exploration of reason" (2007: 174).

La actitud lectora de Kirk parece fundamentarse en elementos vivenciales que suelen aducirse cuando se estudia la obra de Sor Juana: lo difícil de ser mujer en aquellos tiempos, su carácter combativo en el oficio de las letras, el silenciamiento del que fue víctima. Es en este contexto que Kirk minimiza las sospechas que se ciernen sobre la autoría de Sor Juana de la Carta de Serafina de Cristo y hace de esta, así como de la Respuesta a Sor Filotea de la Cruz, los ejes sobre los cuales se 
cimientan su análisis e hipótesis sobre los Enigmas. Así, pues, influida por el estudio de Stephanie Merrim que gira en torno a lo que se conoce como el género de la querelle des femmes ${ }^{7}$, Kirk — restando relevancia al contexto histórico y las evidencias documentales presentes en los manuscritos estudiados por la crítica precedente- toma las quejas de Sor Juana en su Respuesta y las de la otra autora (co el otro autor?) de la Carta de Serafina como pruebas para afirmar que en los Enigmas hay una contundente declaración feminista.

No muy lejos de la interpretación de Kirk, la estudiosa mexicana Yadira Munguía propone soluciones propias para la veintena de acertijos, a los que considera un medio a través del cual Sor Juana cifraría un mensaje disidente que, por el hecho de serlo, debió ser ocultado por la monja, tras su silenciamiento público:

Sor Juana sentía miedo como cualquier otra persona, quiso esconderse, salvaguardarse en algo que la describía a la perfección, algo tan enigmático como ella.

La conjunción de todos los enigmas nos da como resultado uno superior a todos, y solo resolviendo éste sabremos la respuesta de los demás. Tal vez, teniendo la respuesta correcta a todos los enigmas, podríamos formar el rompecabezas del enigma superior a todos: Sor Juana Inés de la Cruz (1999: 26).

La romantización que hace Munguía de la escritura de los Enigmas le impide alejarse de la tendencia — también presente en Kirk- de concebir estos textos demasiado cercanos a las desafortunadas circunstancias biográficas de los últimos años de

Sor Juana y, esto, al mismo tiempo, le impide hacerlos entrar en diálogo con el resto de la obra sorjuanina. Favoreciendo, pues, esta dimensión críptica de los acertijos, Munguía concluye su estudio

7 Ver el excelente estudio que Stephanie Merrim preparó en su libro Early Modern Women's Writing and Sor Juana Inés de la Cruz sobre todo un grupo de mujeres (contemporáneas de Sor Juana) que en el siglo XVII y en diferentes tradiciones literarias escribían textos que pueden aglobarse bajo el género de querelles des femmes y que, sin duda, exhiben posiciones protofeministas. 
adjudicándoles una naturaleza instrumental más allá de lo literario. Los convierte, así, en piezas de un rompecabezas detectivesco al identificar su propósito con la escritura de un mensaje en clave para la Condesa de Paredes, avecindada ya en España: "De este modo los Enigmas no son un pasatiempo, ni una obra literaria más de la Décima Musa; sin duda tienen un por qué y un para qué, incluso un para quién; como antes decía, pueden ser un mensaje en clave, ¿para María Luisa Gonzaga quizás?” (1999: 78).

La lectura de Munguía — al igual que la de Kirk — da la espalda a toda una serie de evidencias documentales que descalifican ipso facto su propuesta de desciframiento. Munguía, por ejemplo, lee el índice del texto - "Índex de los sacrificios que ofrece la Poesía a los sagrados oráculos que ilustraren las obscuridades de los Enigmas"- desoyendo las instrucciones que la mismísima Sor Juana escribió en él, habiendo determinado para cada acertijo el tipo de metro que habría de utilizarse al proponer un desciframiento. Munguía, en cambio, toma el tipo de metro propuesto para cada enigma como una clave para su desciframiento. De allí, se da a la tarea de buscar al interior de los poemas de Sor Juana — que estén versificados en la forma planteada en el índex - pistas que la lleven a encontrar las respuestas para cada uno de los acertijos auxiliándose de su intuición e, incluso, de la numerología.

Así, pues, tras revisar la fortuna crítica y recepción de los Enigmas y con pleno conocimiento de causa de la dificultad que implica un acercamiento a dicho texto, quiero proponer otra lectura de esta obra tan desarropada por la crítica sorjuanina. Mi propuesta ni los considera una piedra filosofal que nos lleve a entender la vida y obra de Sor Juana, ni tampoco una mera rareza dentro del espectro de la producción de la poeta novohispana.

Como afirmé al principio de este ensayo, mi propósito es establecer un diálogo entre los Enigmas y "El sueño" — del cual la propia Sor Juana dijo "no me acuerdo haber escrito por mi gusto si no es un papelillo al que llaman 'El sueño"” (1997. Tomo IV: 471)—, para destacar en dichos acertijos la presencia de una epistemología del cuestionamiento que se 
extiende al espacio de la domesticidad y posibilitar, de esa manera, el ejercicio del entendimiento incluso lejos de la biblioteca.

Para posibilitar ese diálogo entre "El sueño" y los Enigmas, es imprescindible considerar la naturaleza instrumental que tienen en la vida y obra de Sor Juana los libros en tanto medio para acceder al conocimiento, tal como lo detalla una y otra vez en esa autobiografía que es su Carta a Sor Filotea de la Cruz. En la obra de Sor Juana, el conocimiento no es, sin embargo, una actitud exclusivamente receptiva. Para la poeta novohispana el saber implicaba cuestionar aquello que se aprendía. Los libros, pues, más que un depósito del conocimiento, eran un punto de partida para una búsqueda por parte del propio entendimiento de nuevas respuestas a través de las vías de la especulación y el cuestionamiento. En los Enigmas, Sor Juana convoca al entendimiento de sus lectores a realizar una operación semejante a aquella a la que se invitaba en la parte final del Libro de Buen Amor, intitulada "De cómo dice el arçipreste que se ha de entender su libro". En dos de las estrofas de dicho apartado se enfatiza la cualidad instrumental del libro como objeto de conocimiento. Las reproduzco a continuación:

Qualquier omen, que lo oya, si bien trovar sopiere, puede más y añadir et emendar si quisiere, ande de mano en mano a quienquier quel' pidiere, como pella a las dueñas tómelo quien podiere.

Pues es de buen amor, emprestadlo de grado, non desmintades su nombre, nin dedes refertado, non le dedes por dineros vendido nin alquilado, ca non ha grado, nin graçias, nin buen amor complado (Arcipestre de Hita 1998: 1629-1630).

Mi intención no es polemizar sobre la posibilidad — no poco escasa, por cierto- de que Sor Juana haya leído las coplas del Arcipreste y de que, en consecuencia, estas hayan ejercido alguna influencia en la escritura de sus Enigmas. No es que intente establecer vínculos genéticos entre el Libro de Buen Amor y los Enigmas. En su lugar, quiero llamar la 
atención sobre el protagonismo que adquiere el texto (el manuscrito, la copia, para ser estrictos) como vehículo para estimular e impulsar el conocimiento, aunque ambas obras producidas coincidentemente por religiosos (un arcipreste, una monja) velen por sus propósitos a través de la polisemia que engendran en el discurso la selección y combinación de las palabras, así como los registros que se utilizan en ellas.

El Arcipreste invita a los hombres que tuviesen buen entendimiento (trovar) - y esto es esencial para comprender su declaración - a que enmienden y hagan adiciones a sus versos y, además, estimula a que se los haga circular cual objeto lúdico (pella a las dueñas) entre todos los que pudiesen beneficiarse con su lectura. Las estrategias que emplea Sor Juana en su concepción de los Enigmas dialogan con las del Arcipreste, sobre todo en lo que se refiere a la dimensión lúdica de los versos y a su difusión en el seno de una comunidad de lectores que se busca tenga una intervención directa en el texto y en la dialéctica de su significación. Así, en la "Dedicatoria" que antecede a los acertijos, la autora asienta que:

Reverente a vuestras plantas,
solicita, en su disfraz,
no daros que discurrir,
sino sólo que explicar.
Tan feliz será leído,
que ufano dilatará,
los instantes de atención
a siglos de vanidad (vv. 13-20).

Sin embargo, Sor Juana lleva aún más allá que el Arcipreste su concepción de la apertura de la obra literaria ante la comunidad de lectores. Propone sus enigmas no como el centro de la experiencia literaria entre lectores y texto, sino solo como el punto de partida - la ocasión, el pretexto- para que dichos lectores construyan edificios retóricos a través de los cuales se pronuncien alrededor del texto al dar soluciones a cada uno de los veinte acertijos ${ }^{8}$. A través del procedimiento

8 Sor Juana pide que las soluciones sean dadas no en palabras o frases, sino en un argumento que siga determinada métrica y versificación. Después de los enigmas, detalla para cada uno

Bol. Acad. peru. leng. 56(56), 2013 
anterior, Sor Juana otorga una apariencia de divertimiento (disfraz lo llama) a la interacción de sus lectores con el texto, mientras, al mismo tiempo, dota a dicho proceso de una vocación inquisitiva vinculada con el ejercicio de la razón a través del cuestionamiento y la argumentación: "Todo quanto incluye en sí / Por descifrado lo da, / Porque no es yerro en la fe / Proponer, sino dudar" (vv. 25-28).

Es decir, el centro alrededor del cual gira el sentido de los Enigmas no es el de encontrarles la solución (imposible quizá desde el momento en que la propia mente del lector y la de la creadora no son las mismas), sino utilizar el entendimiento y organizar un aparato argumentativo a través del cual el texto se vuelva inteligible ante quien lo intente descifrar. Así, pues, por una parte, Sor Juana está apelando al tópico horaciano del aut delectare aut prodesse est cuando destina su libro a ocupar los momentos de ocio de los lectores para utilizar su atención de manera productiva:

Un descuido vuestro pide, por que, siendo el libro tal, no quedase la atención con yerros de ociosidad (vv. 41-44).

Al mismo tiempo, elabora una dinámica que recuerda la epistemología del cuestionamiento presente ya en "El sueño": la del ser humano en busca de respuestas en medio del gran enigma que es

de ellos el tipo de versificación en que se los debe intentar resolver:

"Index de los sacrificios que ofrece la Poesía a los sagrados oráculos que ilustraren las obscuridades de los Enigmas

$\begin{array}{ll}1^{\circ}: \text { un soneto } & 11^{\circ}: \text { unas liras } \\ 2^{\circ}: \text { dos octavas } & 12^{\circ}: \text { unas endechas endecasílabas } \\ 3^{\circ}: \text { un romance de arte mayor } & 13^{\circ}: \text { unos tercetos } \\ 4^{\circ}: \text { un madrigal } & 14^{\circ}: \text { unas sextillas } \\ 5^{\circ}: \text { un romance vulgar } & 15^{\circ}: \text { unas seguidillas } \\ 6^{\circ}: \text { tres décimas } & 16^{\circ}: \text { una oda } \\ 7^{\circ}: \text { una silva } & 17^{\circ}: \text { unos epílogos } \\ 8^{\circ}: \text { una canción } & 18^{\circ}: \text { unas quintillas } \\ 9^{\circ}: \text { unas endechas vulgares } & 19^{\circ}: \text { un epigrama } \\ 10^{\circ}: \text { un dístico } & 20^{\circ}: \text { unas redondillas" }\end{array}$


el universo en el cual existe. Para el creador, los enigmas (su creación) están descifrados desde el momento en que es él la causa primera de todo cuanto crea. No así para quienes tratasen de comprender dicha creación desde afuera, a través de la razón. A ellos no les estará dado encontrar la respuesta (la verdad, si queremos ceñirnos al argot filosófico-teologal), sino dar aproximaciones que hiciesen de dichos enigmas realidades menos oscuras para el entendimiento:

$$
\begin{aligned}
& \text { Y si, por naturaleza, } \\
& \text { Quanto oculta penetráis, } \\
& \text { Todo lo que es conocer } \\
& \text { Ya no será adivinar (vv. 61-64). }
\end{aligned}
$$

En los versos anteriores que cierran la "Dedicatoria" de los Enigmas, Sor Juana resume la dinámica del conocimiento humano como un esfuerzo hecho de tentativas continuas de desciframiento que se encaminan a conocer lo que solo pueden adivinar. Esta operación que ella requiere de sus lectores en los Enigmas es la misma experiencia por la cual, en "El sueño", el alma humana, en su vuelo metafísico, pretende entender el universo:

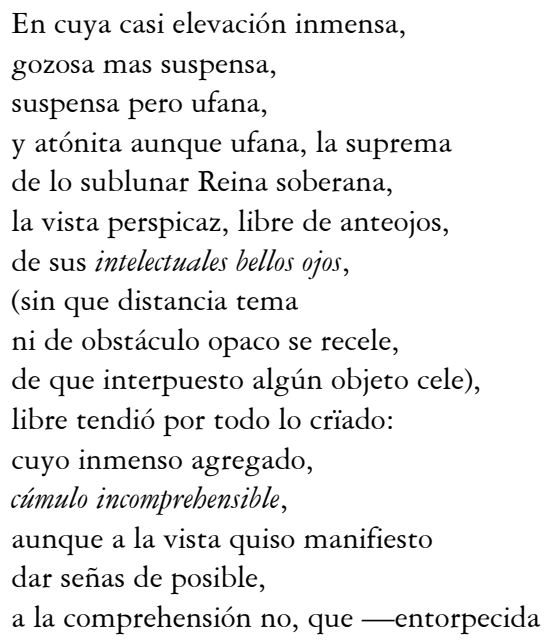


con la sobra de objetos, y excedida

de la grandeza de ellos su potencia-,

retrocedió cobarde (vv. 435-453, las cursivas son nuestras).

Ante lo que Sor Juana denomina "cúmulo incomprensible" (es decir, la visión del universo en su totalidad), el intelecto (o sea, los "intelectuales bellos ojos") fracasa y, entonces, versos más adelante, hará alusión a Faetón y a Ícaro como epítomes de esa ambición humana que, aunque se obstina en querer saber más, es poco lo que consigue. Significativamente, a despecho de la interpretación que se daba en aquel tiempo a dichos mitos como cautionary tales o cuentos sentenciosos, Sor Juana otorga alturas heroicas a las figuras de Faetón y de Ícaro. Subraya, tanto en el pensamiento de Faetón como en el de Ícaro, la centralidad que ocupaba la búsqueda del conocimiento que habría de llevar a ambos a cuestionar y transgredir los límites para, así, acceder al saber:

Otras - más esforzado-

demasiada acusaba cobardía

el lauro antes ceder, que en la lid dura

haber siquiera entrado,

y al ejemplar osado

del claro joven la atención volvía,

—auriga altivo del ardiente carro-

y el, si infeliz, bizarro

alto impulso, el espíritu encendía:

donde el ánimo halla

—más que el temor ejemplos de escarmiento-

abiertas sendas al atrevimiento,

que una ya vez trilladas, no bay castigo

que intento baste a remover segundo,

(segunda ambición, digo).

Ni el panteón profundo

—cerúlea tumba a su infeliz ceniza-,

ni el vengativo rayo fulminante

mueve, por más que avisa,

al ánimo arrogante

que, el vivir despreciando, determina 
su nombre eternizar en su ruina.

Tipo es, antes, modelo:

ejemplar pernicioso

que alas engendra a repetido vuelo,

del ánimo ambicioso

que — del mismo terror haciendo halago

que al valor lisonjea-,

las glorias deletrea

entre los caracteres del estrago (vv. 781-810, las cursivas son nuestras).

Es este intento continuo, este ánimo arrojadizo, la disposición que Sor Juana espera de los lectores de sus Enigmas. Una ética de la osadía intelectual que no se abata ante los muy probables naufragios del entendimiento al intentar descifrar los Enigmas, ni alardee seguridades donde solo quien los escribió podría exhibirlas. Así, pues, el texto de Sor Juana - aunque osado- aspira en gran medida a ser un instrumento para estimular el ejercicio de la razón siempre en los límites estrictos de la ortodoxia religiosa (por lo menos en apariencia). De allí los versos del soneto que sirve de Prólogo a los Enigmas:

Este volumen, cuyo altivo aliento

(benévolo lector, siempre invocado)

generoso presume, aspira osado

remontarse al celeste firmamento,

a tanto sol eleva el pensamiento,

de reverente afecto apadrinado,

que, a soberanas aras destinado, pasa a ser sacrificio el rendimiento.

Piadoso absuelve sus indignidades, que no son en los cultos indecencia que profane devotas atenciones.

Frecuentes votos hacen las deidades, que, a inmunidades de la reverencia, no hay para el cielo cortas oblaciones (las cursivas son nuestras).

De acuerdo con los versos anteriores, Sor Juana concibe el texto de los Enigmas como un Ícaro o un Faetón dirigiendo sus esfuerzos al 
sol, hasta donde eleva el pensamiento. No obstante, al dirigirse hacia el cielo no intenta ningún tipo de asalto - como la rebeldía de los Titanes contra el Monte Olimpo en la mitología griega-, sino, tal vez, como la ambición del alma en "El sueño": aquella de comprender a través del propio entendimiento la arquitectura de la creación; ese querer participar de la razón divina. De allí que Octavio Paz llame a este poema "su autobiografía espiritual" (1993: 500).

El poema que la Condesa de Paredes escribe a los Enigmas corrobora la viabilidad de mi lectura. La otrora virreina de la Nueva España señala en los siguientes versos cómo los veinte acertijos de Sor Juana codifican en su interior cuestiones tan profundas (a las cuales relaciona con lo inconmensurable), que ella misma se declara incapaz de intervenir en la resolución de los mismos; además, define estas problemáticas a las que apelan los Enigmas a través de la díada en oxímoron de "claridades oscuras":

\author{
Misterios son que no toco \\ estos Enigmas que leo, \\ para que en lo inteligible \\ no peligrase lo inmenso. \\ Sólo tu Musa hazer pudo, \\ con misterioso desvelo, \\ de claridades obscuras, \\ lo no entendido, discreto (vv 13-20, las cursivas son nuestras).
}

Sor Juana expande el radio de acción de estas claridades oscuras al espacio del puro divertimiento doméstico y las instala en los acertijos. $\mathrm{Al}$ infundir una dimensión especulativa a este género que, en apariencia, no distaba mucho de esas "filosofías de cocina" a las que se había referido en su Respuesta como únicas adecuadas para las mujeres, Sor Juana convierte a estos enigmas en otro más de los campos de batalla de su entendimiento. Esto no implica que subyazca en dichos textos un proyecto de comunidad exclusivamente femenina de lectoras contra el sistema patriarcal. Ateniéndome a marcas claras en el texto, puedo decir que los Enigmas ni son una declaración ardiente de feminismo, ni su lectura fue 
pensada por la autora como exclusiva de las monjas portuguesas de la Casa do Prazer (que, a su vez, tampoco era una academia literaria clandestina), ni mucho menos albergan en su interior mensajes en clave para determinada persona. Si bien es cierto que Sor Juana dedicó sus Enigmas a las referidas monjas portuguesas, no podemos asumir que no desease la circulación y la discusión de su texto como en efecto ocurrió durante todo el siglo XVIII en Portugal, y gracias a lo cual lograron conservarse hasta nuestros días. Los Enigmas, pues, deben ser leídos como otra manifestación de su epistemología del cuestionamiento; como la expansión a la esfera de la domesticidad del ejercicio del entendimiento inquisitivo de Sor Juana (despojada ya para entonces de su cara biblioteca), pero también de todos quienes se envolviesen en el juego que la poeta novohispana sigue proponiendo a través de ellos. 


\section{BIBLIOGRAFÍA}

ALATORRE, Antonio. Sor Juana Inés de la Cruz: Enigmas ofrecidos a la Casa del Placer. México, El Colegio de México, 1994.

ARCIPRESTE DE HITA. Libro de Buen Amor. Madrid, Cátedra, 1998.

DE LA CRUZ, Sor Juana Inés. Obras completas. México, Fondo de Cultura Económica, 1997.

KIRK, Stephanie L. Convent Life in Colonial Mexico. A Tale of Two Communities. Gainesville, University Press of Florida, 2007.

MARTÍNEZ LÓPEZ, Enrique. "Sor Juana Inés de la Cruz en Portugal: Un desconocido homenaje y versos inéditos". En: Revista de Literatura $\mathrm{N}^{\circ} 33,1968$, pp. 33-54.

MERRIM, Stephanie. Early Modern Women's Writing and Sor Juana Inés de la Cruz. Nashville, Vanderbilt UP, 1999.

MORINO, Angelo. "Los enigmas de Juana Inés de la Cruz. Ensayo de traducción al italiano". En: Artifara 2, Dipartamento de Scienze Letterarie e Filologiche-Università degli Studi di Torino: enero-junio 2003. http://www.cisi.unito.it/Artifara/ Rivista2/testi/enigmas.asp. 17 de marzo de 2008.

MUNGUÍA, Yadira. Respuesta a los enigmas de Sor Juana. Guadalajara, Casa Museo López Portillo, 1999.

PAZ, Octavio. Sor Juana Inés de la Cruz o las trampas de la fe. México, Fondo de Cultura Económica, 1993.

PEÑA, Margarita. Prodigios Novohispanos. Ensayos sobre literatura de la Colonia. México, Universidad Nacional Autónoma de México, 2005. 
SABAT DE RIVERS, Georgina. "Contemporáneos de Sor Juana; las monjas portuguesas y los Enigmas (con soluciones)". En: En busca de Sor Juana. México, Universidad Nacional Autónoma de México, 1998, pp. 205-37.

\section{Correspondencia:}

\section{Jesús Ernesto Ortiz-Díaz, Ph.D.}

Assistant Professor. Department of Hispanic Studies/Program of Latin American Studies. 220 Humanities Building. Macalester College.

Correo electrónico: molsen@macalester.edu 